\title{
AN EXAMINATION OF FERTILITY OF WOMEN FOLLOWING PREGNANCY ACCORDING TO HEIGHT AND WEIGHT
}

\author{
BY \\ THOMAS MCKEOWN AND R. G. RECORD \\ Department of Social Medicine, University of Birmingham
}

Although there is reason to believe that differential fertility of biological origin helps to maintain genetic stability, it is by no means easy to obtain acceptable evidence of this phenomenon in man. There are at least two difficulties. In the first place it is technically difficult to record the subsequent fertility of individuals on whom a character such as intelligence, stature, weight etc. has been measured. What is usually noted is the correlation between a character and the number of sibs, an observation much more difficult to interpret. Secondly, the variation in fertility to be expected on theoretical grounds is such that very large numbers of observations would probably be required to establish it. Some objections to conclusions based upon metrical characters such as birth weight have been discussed elsewhere (McKeown, 1956).

An investigation of approximately a thousand representative women during and after pregnancy provided an opportunity to observe the incidence of conception in the two years after delivery. The observation has been used as an index of fertility, and this report examines its relation to maternal age, parity, height, and weight, and to an index of body build.

\section{Methods}

The observations were derived from an investigation of pregnancies of all mothers, domiciled in the County Borough of Smethwick, whose children were born between April 1, 1949 and March 31, 1950. A full account of the data has been given previously (McKeown and Record, 1957a), and here we shall refer only to those features related to the examination of fertility.

(a) Height and Weight of Mother.-These were measured at the first antenatal examination, and the weight also at $3,6,9,12$, and 24 months after delivery. (An index of body build was derived from the observed regression of the weight at 3 months on height.) Women were divided into five groups according to whether they were:
A. More than 15 per cent. below expected weight.
B. 5-15 per cent. below expected weight.
C. Within 5 per cent. of expected weight.
D. 5-15 per cent. above expected weight.
E. More than 15 per cent. above expected weight.

(b) Fertility.-After examination of various indices of fertility, the incidence of conception within 2 years after delivery was considered to be the most satisfactory for the present purpose. For the first 12 months of this period women recorded their menstrual cycles in a diary and the date of the last menstrual period preceding pregnancy is known. Information about pregnancy in the second year was obtained by interrogating the mother at 24 months, and the date of onset is therefore less exactly known. A few conceptions in the last months were undoubtedly missed by women who were not aware that they were pregnant when seen at 24 months.

1,266 mothers gave birth to single liveborn children in the 12-month period (April, 1949March, 1950), but 39, whose infants died in the first year after birth, were excluded. Antenatal, birth, and postnatal records were available for 1,118 of the remaining 1,227 women, and age and parity were known for 1,110. However, 171 of these women were untraced 2 years after delivery, and the observations which follow are based on the remaining 939. 


\section{RESULTS}

195 (20.8 per cent.) of the 939 women traced at 2 years after delivery became pregnant within that period, and five of these conceived twice. Fig. 1 shows the mean number of pregnancies known to have begun before each month until the 15 th, and a straight line has been fitted to the points. After 15 months the date of onset of gestation is less accurately known, and since, for obvious reasons, no pregnancies were recorded in the last 2 months, the records are evidently reasonably complete only until 22 months. The proportion of women who had conceived by 22 months $(20.8$ per cent.) is shown in Fig. 1, and the straight line fitted to the earlier data has been extended (by a dotted line).

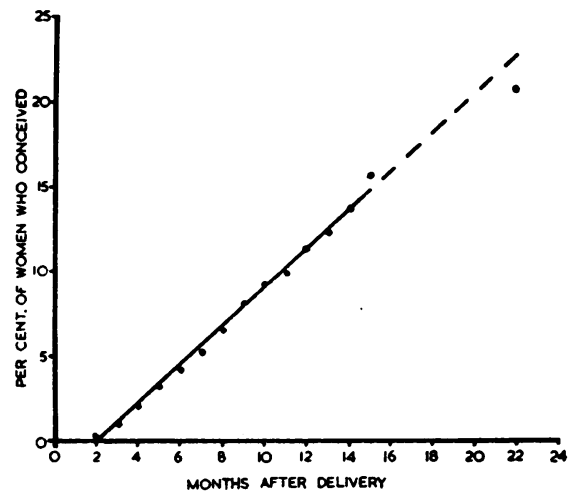

FIG. 1.-Cumulative incidence of conception within 24 months of delivery.

Since it is quite likely that a few early pregnancies were missed in the months immediately before the 22nd, the total cumulative incidence at that time is probably a little low. It is concluded that the cumulative proportions of women who became pregnant in each month after birth fall on a straight line, at least until the 22nd month.

Table I gives the incidence of conceptions within 24 months according to age and parity. The relationship is quite consistent: within each parity the proportion of women who became pregnant declines with age; within each age group after the first (under 25) the trend with parity is U-shaped, incidence being lowest for women who had two pregnancies (including the one just completed at the beginning of the 2-year period). The relationship is examined further in Fig. 2, which gives the cumulative incidence of conceptions for two age groups within each parity. In each case the frequency of conception is greater for the younger women.

TABLE I

INCIDENCE OF CONCEPTIONS (PER CENT.) WITHIN 24 MONTHS AFTER DELIVERY ACCORDING TO AGE AND PARITY

\begin{tabular}{|c|c|c|c|c|c|c|c|c|c|c|}
\hline \multirow{3}{*}{ Parity } & \multicolumn{8}{|c|}{ Age (yrs) } & \multicolumn{2}{|c|}{ All Ages } \\
\hline & \multicolumn{2}{|c|}{ Under 25} & \multicolumn{2}{|c|}{$25-29$} & \multicolumn{2}{|c|}{$30-34$} & \multicolumn{2}{|c|}{$\begin{array}{l}35 \text { and } \\
\text { Over }\end{array}$} & \multirow[b]{2}{*}{ No. } & \multirow{2}{*}{$\begin{array}{c}\text { Per } \\
\text { cent. }\end{array}$} \\
\hline & No. & $\begin{array}{c}\text { Per } \\
\text { cent. }\end{array}$ & No. & $\begin{array}{c}\text { Per } \\
\text { cent. }\end{array}$ & No. & $\begin{array}{c}\text { Per } \\
\text { cent. }\end{array}$ & No. & $\begin{array}{c}\text { Per } \\
\text { cent. }\end{array}$ & & \\
\hline $\begin{array}{l}1 \\
2\end{array}$ and Over & $\begin{array}{r}184 \\
76 \\
20\end{array}$ & $\begin{array}{l}25 \cdot 0 \\
31 \cdot 6 \\
50 \cdot 0\end{array}$ & $\begin{array}{r}121 \\
109 \\
83\end{array}$ & $\begin{array}{l}17 \cdot 4 \\
13 \cdot 8 \\
26 \cdot 5\end{array}$ & $\begin{array}{l}48 \\
56 \\
95\end{array}$ & $\begin{array}{l}16 \cdot 7 \\
10 \cdot 7 \\
22 \cdot 1\end{array}$ & $\begin{array}{r}9 \\
31 \\
107\end{array}$ & $\begin{array}{r}11 \cdot 1 \\
6 \cdot 5 \\
17 \cdot 8\end{array}$ & $\begin{array}{l}362 \\
272 \\
305\end{array}$ & $\begin{array}{l}21 \cdot 0 \\
17 \cdot 3 \\
23 \cdot 6\end{array}$ \\
\hline All Parities & 280 & $28 \cdot 6$ & 313 & $18 \cdot 5$ & 199 & $17 \cdot 6$ & 147 & $15 \cdot 0$ & 939 & $20 \cdot 8$ \\
\hline
\end{tabular}

The examination of fertility according to height and weight is based on 918 (of the 939) women; weight or height was unknown for the remaining 21 , of whom five became pregnant within the 2 years.
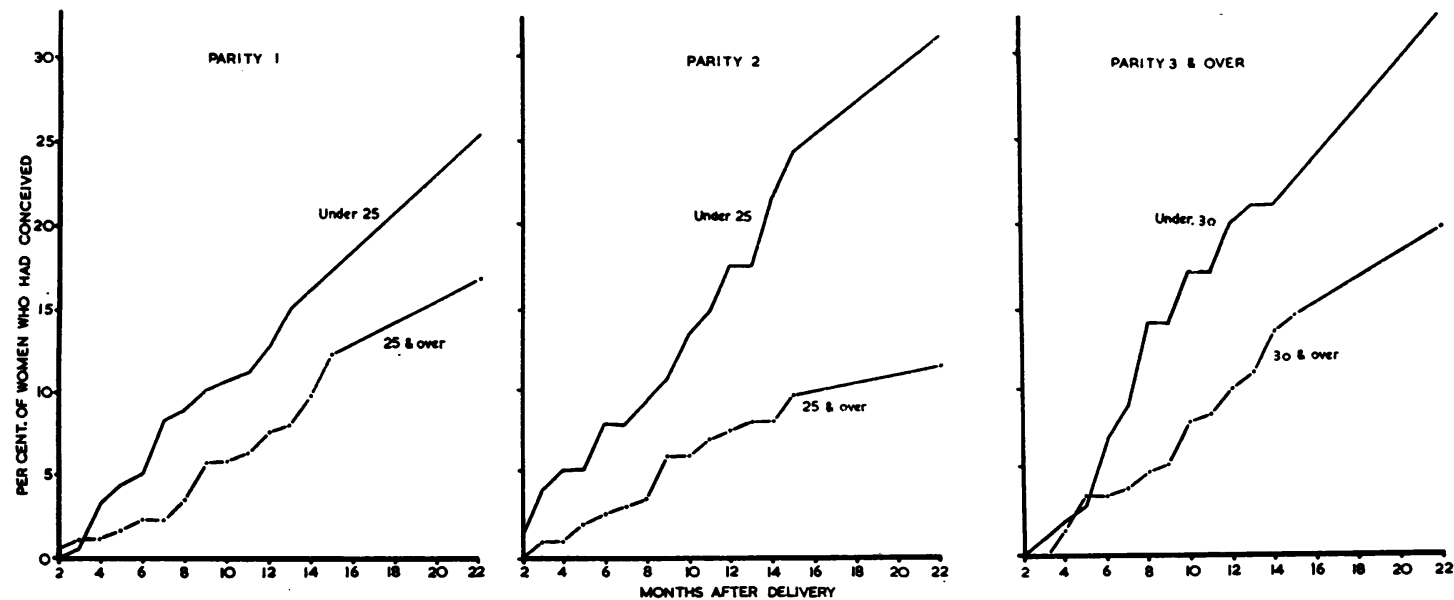

FIG. 2.-Cumulative incidence of conception within 24 months of delivery, related to age and parity. 
The incidence of conception is given in Table II for five weight groups, and, because of the marked association between fertility and age and parity, the data have been standardized to remove the influence of these variables. The only noteworthy association is the low incidence of pregnancy in women in the heaviest group (170 lb. and over).

TABLE II

FERTILITY* RELATED TO WEIGHT

\begin{tabular}{c|c|c|c|c}
\hline $\begin{array}{c}\text { Weight 3 mths } \\
\text { after Delivery } \\
\text { (lb.) }\end{array}$ & $\begin{array}{c}\text { No. of } \\
\text { Women }\end{array}$ & $\begin{array}{c}\text { No. who } \\
\text { Conceived }\end{array}$ & \multicolumn{2}{|c|}{$\begin{array}{c}\text { Percentage who } \\
\text { Conceived }\end{array}$} \\
\cline { 2 - 4 } & & Crude & $\begin{array}{c}\text { Standard- } \\
\text { izedt }\end{array}$ \\
\hline Under 110 & 121 & 24 & $19 \cdot 8$ & $21 \cdot 0$ \\
$110-129$ & 301 & 70 & $23 \cdot 3$ & 22.9 \\
$130-149$ & 292 & 64 & $21 \cdot 9$ & $22 \cdot 3$ \\
$150-169$ & 131 & $16 \cdot 8$ & $19 \cdot 0$ \\
170 and Over & 73 & 10 & $13 \cdot 7$ & $11 \cdot 1$ \\
\hline Total & 918 & 190 & $20 \cdot 7$ & - \\
\hline
\end{tabular}

* In this and subsequent Tables, fertility refers to the incidence of conception within 24 months after delivery.

$t$ To remove influence of age and parity.

The relationship to height (Table III) is less marked, and on the number of observations available there is little evidence that fertility is related to this variable.

TABLE III

FERTILITY RELATED TO HEIGHT

\begin{tabular}{c|c|c|c|c}
\hline & No. of & No. who & \multicolumn{2}{|c|}{$\begin{array}{c}\text { Percentage who } \\
\text { Conceived }\end{array}$} \\
\cline { 3 - 4 } Height (in.) & Women & Conceived & Crude & $\begin{array}{c}\text { Standard- } \\
\text { ized * }\end{array}$ \\
\hline Under 62 & 163 & 36 & 22.1 & 22.9 \\
62 and 63 & 243 & 56 & 23.0 & 22.8 \\
64 and 65 & 306 & 58 & 19.0 & 19.4 \\
66 and Over & 206 & 40 & 19.4 & 19.0 \\
\hline Total & 918 & 190 & 20.7 & - \\
\hline
\end{tabular}

* To remove influence of age and parity.

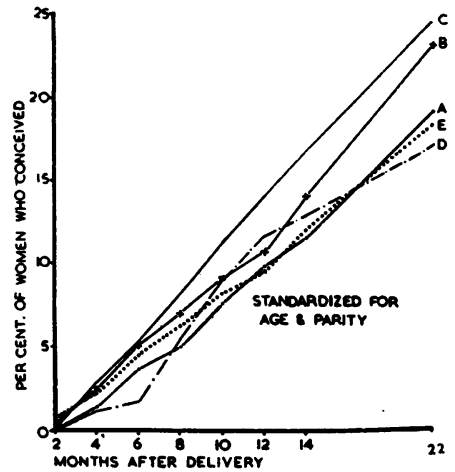

Fig. 3.-Cumulative incidence of conception within 24 months of delivery, related to body build.
Fertility was also examined (Table IV) in relation to body build, by using the five sub-groups referred to above. The incidence of conception is greatest ( 24.7 per cent. after standardization) in women within 5 per cent. of the expected weight for height.

TABLE IV

FERTILITY RELATED TO BODY BUILD

\begin{tabular}{|c|c|c|c|c|c|c|c|}
\hline \multicolumn{2}{|c|}{ Body Build Group. . $\quad \ldots$} & A & B & C & $\mathbf{D}$ & E & Total \\
\hline \multirow{2}{*}{\multicolumn{2}{|c|}{$\begin{array}{l}\text { No. of Women } \\
\text { No. of Women who } \\
\text { Conceived. . }\end{array}$}} & & 230 & 247 & 142 & 153 & 918 \\
\hline & & 26 & 51 & 60 & 26 & 27 & 190 \\
\hline \multirow[b]{2}{*}{$\begin{array}{l}\text { Incidence of } \\
\text { Conceptions } \\
\text { (per cent.) }\end{array}$} & (a) Crude .. & $17 \cdot 8$ & $22 \cdot 2$ & $24 \cdot 3$ & $18 \cdot 3$ & $17 \cdot 6$ & $20 \cdot 7$ \\
\hline & $\begin{array}{l}\text { (b) Standard- } \\
\text { ized for } \\
\text { Age and } \\
\text { Parity... }\end{array}$ & $19 \cdot 2$ & $23 \cdot 3$ & $24 \cdot 7$ & $17 \cdot 4$ & $18 \cdot 5$ & - \\
\hline
\end{tabular}

The data are shown as cumulative percentages at 2-monthly intervals after delivery in Fig. 3.

In a previous examination of the relation between body build and weight changes associated with pregnancy (McKeown and Record, 1957c) it was noted that there was a considerable difference in the experience of women according to their height. It therefore seemed worthwhile to explore the association between fertility and body build, while also taking account of height. For this purpose, because of small numbers it has been necessary to reduce the five groups to three, by combining the two groups more than 5 per cent. below the expected weight for height (A and B) and the two groups more than 5 per cent. above it (D and E). The data are given separately for women in four height groups, and the results have again been standardized to correct for the influence of age and parity (Fig. 4).
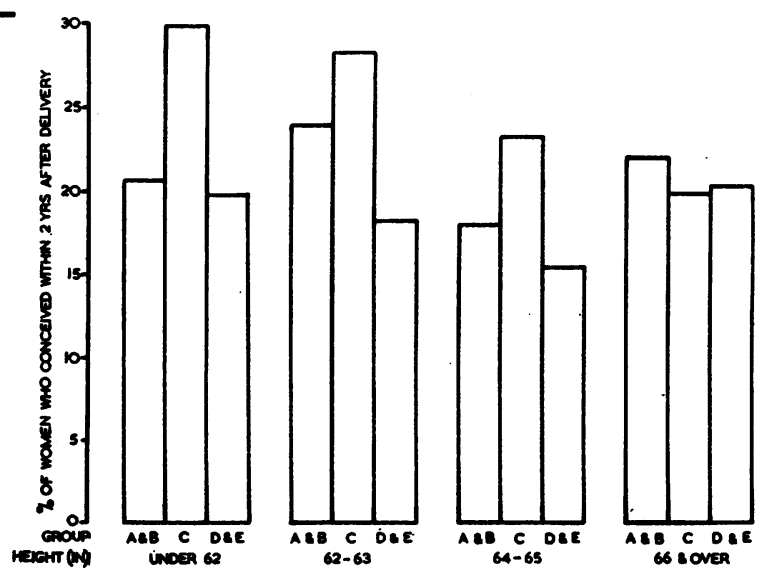

FIG. 4.-Fertility related to height and body build. 
In three height groups (under 62, 62-63, and 64-65 in.), the frequency of conception is highest among women within 5 per cent. of the expected weight for height; in the fourth height group (66 in. and over) there is little difference between the three body build groups.

\section{Discussion}

It should be said at once that, for assessment of the relationship between fertility and variables such as height, weight, and body build, neither the present population of women, nor the index of fertility employed, is beyond criticism. In the first place, being restricted to women who had completed at least one pregnancy, the data exclude infertile women, and it is possible that the relationship would be different if these were included. Secondly, the frequency of conception within 2 years of delivery is not an ideal index of fertility. We are fairly satisfied that the results are little affected by the duration of lactation, which was shown to be unrelated to weight or body build (McKeown and Record, 1957b). A more serious objection is that we have no information about the influence of contraception, and data examined by Gioiosa (1955) suggest that the frequency of conception within 2 years of delivery is much higher than 20 per cent. (the level here recorded) in a group of women among whom reproduction is unrestricted. Whether the use of contraceptives affects the relationship of fertility to variables such as height and weight is an open question, but the fact that well-to-do women are taller and have smaller families than poor women suggests that it might. On the other hand, the population of women was drawn from a workingclass area in which variation in social circumstances was small.

In spite of these reservations it seemed well worth while to take the opportunity provided by a careful record of menstruation following pregnancy, to examine the relationship between fertility and height, weight, and body build. On the numbers of observations available the results must be interpreted cautiously, but the evidence in Fig. 4 suggests that fertility may be somewhat greater in women who are close to the average body build than in those who are fat or thin. It should be noted that if this conclusion is accepted-and the data are regarded as no more than suggestive-it scarcely justifies a generalization about the relationship between fertility and other continously distributed characters such as height. For it seems probable that the incidence of pathologieal conditions associated with low fertility is higher in fat or thin women than in tall or short women.

\section{SUMMARY}

The incidence of conception within 2 years after delivery of a previous child ( 20.8 per cent.) was used as an index of the fertility of 939 women. Fertility declined with age; the trend in association with parity was U-shaped, incidence of conception being lowest in women who had had two previous pregnancies. The only evidence of association between fertility and weight or height was a low incidence of conception (11.1 per cent.) among the 73 women in the heaviest weight group (170 $\mathrm{lb}$. and over).

The observed regression of weight on height was used to divide women into five groups according to body build. The data suggest that fertility is somewhat higher among women within 5 per cent. of the expected weight for height than in those above or below this level.

\section{REFERENCES}

Gioiosa, R. (1955). Amer. J. Obstet. Gynec., 70, 162.

McKeown, T. (1956). Proceedings of the First International Congress of Human Genetics, Copenhagen, August, 1956. Acta genet. statist. med. (in the press).

- and Record, R. G. (1957a). J. Endocrinol., 15 (in the press). (1957b). Ibid. 